for completed stroke. Serial arteriography has shown that such anastomoses can enlarge to supply a major proportion of one cerebral hemisphere, ${ }^{67}$ and long-term patency rates are high. ${ }^{8} 9$

Despite the undoubted technical success of the procedure in supplying additional blood to the brain, the indications for its use are by no means clear cut. There are few data, especially in the longer follow-up, of the effect of the operation on symptoms such as TIAs and in preventing completed strokes. The operative mortality appears to be low in reported series, ${ }^{8} 9$ but there may be some morbidity, including neurological deficit related to the operated cerebral hemisphere. ${ }^{9}{ }^{10}$ Selecting patients for operation usually requires detailed arteriography to discover the state of the intracranial and extracranial vessels and often the aortic arch as well. These procedures carry some risk of producing a stroke, though this is small in centres where arteriography is regularly carried out. By no means all physicians, however, are prepared to recommend such investigations for their patients, often elderly, who may have no neurological deficit. Newer non-invasive techniques such as oculoplethysmography, carotid phonangiography, ${ }^{11}$ and Doppler imaging ${ }^{12}$ may reduce the need for angiography in patients who are shown not to be suitable for reconstructive surgery. Nevertheless arteriography will still be needed if surgical treatment is being considered in patients with TIAs or prolonged reversible deficit in whom these non-invasive methods have shown no extracranial vascular disease.

A major international multicentre trial has been set up to compare the results in patients treated by extracranial-tointracranial anastomosis with controls treated by drugs. ${ }^{13}$ The trial is mainly concerned with patients with prestroke conditions, and the aim will be to determine whether the surgical procedure reduces completed strokes by over half when compared with medically treated controls. Some patients will also be included with completed strokes but with considerable retained function in the affected hemisphere and with ability to look after themselves. The concept of restoring latent function to an ischaemic hemisphere by increasing the blood supply is attractive and some encouraging results are reported in this issue ${ }^{9}$ (see also $\mathrm{p} \mathrm{18}$ ). So far the major use of the anastomotic procedure has been in preventing stroke, and it seems unlikely that improving the blood flow to a cerebral hemisphere with severe long-standing ischaemic damage could be helpful. Nevertheless, less severely affected hemispheres might have function improved, especially if patients show fluctuations in neurological deficit, suggesting poor cerebral perfusion.

The international trial is expected to last for some years, and in view of the uncertainties, both about the clinical indications for the procedure and about the long-term results, the results will be awaited with some impatience. The selection and evaluation of these patients, the detailed investigation, and the special microsurgical skills required demand a multidisciplinary approach most likely to be found in specialist centres where neurologists, neurosurgeons, neuroradiologists, and vascular surgeons work closely together. Such an approach is likely to produce the best results and also determine the future place of the procedure in the management of patients with cerebral ischaemia.

${ }^{1}$ Fields, W S, et al, fournal of the American Medical Association, 1970, 211, 1993.

2 Thompson, J R, Simmonds, C R, and Tsao, E, in Microneurosurgical Anastomoses for Cerebral Ischemia, ed G M Austin, p 157. Springfield, Thomas, 1976.

${ }^{3}$ Woolsey, R M, and Hambrook, G W, Stroke, 1973, 4, 7.
4 Donaghy, R M P, and Yasargil, M G, Progress in Brain Research, 1968, 30, 263.

5 Yasargil, M G, Microsurgery Applied to Neurosurgery, p 105. Stuttgart, Thieme, 1969.

${ }^{6}$ Spetzler, R, and Chater, N, fournal of Neurosurgery, 1976, 45, 508.

7 Gratzl, O, et al, in Microneurosurgical Anastomoses for Cerebral Ischemia, ed G M Austin, p 308. Springfield, Thomas, 1976.

${ }^{8}$ Chater, N, Peerless, S J, and Weinstein, P R, in Microsurgical Anastomoses for Cerebral Ischemia, ed J M Fein and O H Reichman, p 290. New York, Springer, 1978 .

${ }^{9}$ Zumstein, B, Yasargil, M G, and Yonekawa, Y, in Progress in Stroke Research I, ed R M Greenhalgh and F C Rose, p 404. Tunbridge Wells, Pitman, 1979, in press.

10 Samson, D S, Hodosh, R M, and Clark, W K, fournal of the American Medical Association, 1979, 241, 376.

${ }_{11}$ Yao, J S T, Verta, M J, and Bergan, J J, in Progress in Stroke Research I, ed R M Greenhalgh and F C Rose, p 270. Tunbridge Wells, Pitman, 1979 , in press.

12 Gosling, R G, and Lewis, R R, in Progress in Stroke Research I, ed R M Greenhalgh and F C Rose, p 247. Tunbridge Wells, Pitman, 1979, in press.

13 Stroke, 1977, 8, 545.

\section{Community medicine: a change in direction}

Community physicians are mostly aged over 50 , and recruitment to the specialty is not keeping pace with deaths and retirement. Within the next five years their total numbers in the NHS are expected to fall to around 500-a substantial decline from the 1200 doctors in the public health and medical administration services before the reorganisation of the Health Service. At their recent annual conference community medicine representatives discussed the future of their specialty (30 June, $\mathrm{p} \mathrm{1809)}$ and the unarguable fact is that young doctors are not attracted to community medicine as organised at present.

The reason, says the Unit for the Study of Health Policy (USHP) in a report ${ }^{1}$ just published, is that community physicians have concentrated their attention on medical administration and the organisation of NHS services at the expense of tackling the problems of environmental health. Community medicine has been silent, says the report, on major contemporary issues such as pollution, housing policy, and technological developments and by its silence has condoned the mistaken belief that the prevention of illness is solely a matter of individual concern.

What the USHP proposes is that community medicine should switch its emphasis to prevention. It suggests setting up health promotion teams (roughly one to every two local authority areas) whose primary function would be to act as watchdogs - to bring into the public view any health hazards arising from industrial practices, planning decisions, transport policies, recreation, and housing. They could also provide expert advice-for example, for schools on nutrition-and monitor the health of the local population, presenting an annual report along the lines of those formerly published by medical officers of health.

These local health promotion teams would need to be backed up centrally, and the USHP report suggests that detailed examination of the health implications of governmental actions could be one of the functions of the new parliamentary select committees which the current Government has agreed to set up. If given health as its main concern-and given power to call for evidence from civil servants and to question ministers - such a committee could exert a powerful influence on legislation and governmental action.

Perhaps the most radical proposal in the report is that much of the work of health promotion teams could be done by non- 
medical experts-"community health advisers." Many of the current functions of specialists in community medicine could be undertaken by these advisers, says the report-solving at a stroke the problems now attributed to shortage of staff and saving money on both salaries and training.

Clearly a brief report (126 pages) can only outline the USHP proposals, but they warrant serious attention by community physicians. Radical changes are needed to deal with the low morale in the specialty and poor recruitment. The concentration on administration and committee work that has characterised the infancy of the specialty seems likely to be seen, with hindsight, as mistaken. It is by no means too late for a change in direction.

${ }^{1}$ Unit for the Study of Health Policy, Rethinking Community Medicine: Towards a Renaissance in Public Health? USHP, 8 Newcomen Street, London SE1 1YR (price $£ 2 \cdot 50$ ), 1979.

\section{Infective endocarditis with negative blood cultures}

Though infective endocarditis.can now be cured, the death rate is still $30 \%{ }^{12}$ Patients die not of uncontrolled infection but of the late mechanical effects of their destructive lesions, often causing gross heart failure. ${ }^{3} \mathrm{~A}$ major factor in this story is delay in presentation, in diagnosis, and in starting treatment once the diagnosis is suspected rather than waiting for bacteriological proof. One group of patients which fares particularly badly are those with endocarditis but persistently negative blood cultures. While criteria for its diagnosis vary, this group forms an average of $20 \%$ of most published series. Attempts to reduce this proportion have been only partially successful even in the best centres using modern laboratory techniques.

Endocarditis, which is usually caused by streptococci, may also be caused by a group of fastidious Gram-negative rods that are rarely pathogenic in man. They are Haemophilus aphrophilus ( $H$ influenzae rarely causes endocarditis), ${ }^{4}$ Actinobacillus actinomycetemcomitans, ${ }^{5}$ Cardiobacterium hominis, ${ }^{6} 7$ and Streptobacillus moniliformis. ${ }^{7}$ They are all rare causes, accounting for only a tiny proportion of the "difficult" cases. We now know that Staphylococcus epidermidis and diphtheroid bacilli, commonly associated with postoperative endocarditis, may cause non-operative endocarditis, usually in older people. Coxiella burneti, ${ }^{9}$ Chlamydia psittaci $^{10}$ and $C$ trachomatis ${ }^{11}$ have been recognised as non-bacterial causes of endocarditis, and account for some of the cases with negative blood cultures. It is important to recognise this possibility, as the treatment for organisms which lack a rigid cell wall is radically different: penicillins are ineffective and long-term tetracyclines are required. A viral aetiology for culture-negative endocarditis has been postulated but there is no good evidence for this, in spite of the Coxsackie group being commonly associated with myocarditis and pericarditis. If viral endocarditis does occur it is exceedingly rare.

Many physicians still seem uncertain about the best approach to treatment for patients who are culture-negative. Some at least are known to respond to the combination of benzylpenicillin and an aminoglycoside. These should be used as initial treatment for all cases of non-operative endocarditis whether culture-negative or culture-positive. Metabolically aberrant, thiol-dependent streptococci (satelliting streptococci $)^{12}$ respond to the combination but not usually to penicillin alone. These organisms, which require a source of sulphydryl groups, often grow well in the blood culture bottle but slowly, if at all, on routine solid media. What about patients who have been given antibiotics before admission-often without a diagnosis of endocarditis having been made? Many such patients have negative blood cultures when they present, ${ }^{13} 14$ even though the treatment given has usually been inappropriate and will always have been incomplete. How many cases of endocarditis are actually rendered culture-negative is not clear. One case has been reported where unintentional administration of a single dose of penicillin rendered cultures negative for 17 days. ${ }^{15}$ Again, however, the best treatment option is a combination of benzylpenicillin and an aminoglycoside.

A recent publication from Iowa ${ }^{16}$ clarifies the problem of culture-negative cases in general, and the effect of prior antibiotic administration in particular. It is a retrospective study of a heterogeneous series of 52 culture-negative cases. Twentyone occurred over the same period as 84 culture-positive cases, giving the expected $20 \%$ ratio. The culture-negative cases were indistinguishable on presentation from those with positive cultures. Some responded rapidly to treatment, but the response and survival of culture-negative cases were similar to those cases with the worst prognosis: those caused by Staph aureus, and infections affecting prosthetic valves. Thirty of the 52 culture-negative cases survived, two-thirds of them responding rapidly to treatment. Valvular tissue was examined from 19 of the 22 patients who died and from six who underwent valve surgery. In four no evidence of endocarditis was seen. In 15 organisms were seen, and in nine of these were grown. Most were Gram-positive cocci, but other bacteria appeared to have been present. Some may have represented postmortem contamination but most clearly did not. The report includes three atypical cases in which blind treatment was delayed for two weeks or more because of uncertainty about the diagnosis. All had received antibiotics previously and all yielded streptococci from cultures taken after this considerable waiting period. The study suggests that culturenegative cases are usually caused by common bacteria, rendered inaccessible by the age of the lesion or the prior use of antibiotics, rather than unusual bacteria such as brucella or bacteroides.

Definitive treatment of non-operative cases of bacterial endocarditis with benzylpenicillin and gentamicin should be started at once without awaiting results. Long delays in the hope of obtaining a positive culture will rarely prove fruitful, and may be catastrophic. Treatment with antibiotics should be continued for six weeks, as in culture-positive cases, and should be stopped only in those rare cases where a definite alternative diagnosis is forthcoming.

1 Hayward, G W, British Medical fournal, 1973, 2, 706.
2 Hayward, G W, British Medical fournal, 1973, 2, 764.
3 Wise, J R, et al, Lancet, 1971, 2, 115.
4 Geraci, J E, et al, Mayo Clinic Proceedings, 1977, 52, 209.
5 Vandepitte, J, Geest, H de, and Jousten, P, fournal of Clinical Pathology,
1977, 30, 842.
Jobanputra, R S, and Moysey, J, fournal of Clinical Pathology, 1977, 30,
1033.
7idgley, J, et al, fournal of Medical Microbiology, 1970, 3,91.
8 Andrews, P S, and Marmion, B P, British Medical fournal, 1959, 2, 983.
Robson, A O, and Shimmin, C D E L, British Medical fournal, 1959, 2,
980.
10 Levison, D A, et al, Lancet, 1971, 2, 844.
11 van der Bel-Kahn, J M, et al, American Heart fournal, 1978, 95, 627.
12 McCarthy, L R, and Bottone, E J, American fournal of Clinical Pathology,

12 McCarthy, L R, and Bottone, E J, American fournal of Clinical Pathology, 1974, 61, 585.

13 Smith, R H, et al, Thorax, 1976, 31, 373.

14 Werner, A S, et al, fournal of the American Medical Association, 1967, 202, 199.

15 Balme, H W, and Dormer, A E, British Medical fournal, 1954, 1, 500.

16 Pesanti, E L, and Smith, I M, American fournal of Medicine, 1979, 66, 43. 